\title{
Use of Organic Waste Compost for Home-Based Science Learning at Elementary School in Sigi
}

\author{
Vivien Cicilia \\ Dinas Pendidikan dan Kebudayaan Kabupaten Sigi \\ Sigi, Indonesia \\ vivienpian98@gmail.com \\ Daud K Walanda \\ Lecturer Lecturer/Head of Science Education \\ Tadulako University \\ Palu, Indonesia \\ walanda@gmail.com
}

\author{
Deitasmalina Musa \\ Dinas Pendidikan dan Kebudayaan Kota Palu \\ Palu, Indonesia \\ deitasmalinamusa1977@gmail.com
}

\begin{abstract}
Organic waste is defined as unused objects derived from activity and solid form. In this case, it can be found in school environments according to the number of students each day. This study aims to describe the utilization of organic waste from compost house based on science learning in primary school from BLH Sigi. The type of this study is a quantitative research. The samples of the research are students of grade $5^{\text {th }}$ and $6^{\text {th }}$ of SDN 1 Biromaru and SD Inpres Kotapulu Sigi district. The instrument used is questionnaire which gains the information of the benefits of organic waste on science learning, student character, and school environment. The data of the research will be analyzed to indicate the potential of organic waste in SDN 1 Biromaru and SD Inpres Kotapulu. It is found that utilizing the compost house produced by the student grade $5^{\text {th }}$ and $6^{\text {th }}$ is $1067,5 \mathrm{gram} / \mathrm{day}$. As the final result, the organic waste is used for coaching the character of students, and the benefits for the environment.
\end{abstract}

Keywords: organic waste, composting, and learning science

\section{INTRODUCTION}

Composting is not a new technology. It is an aerobic biological process where microorganisms convert organic materials (manure, sludge, leaves, paper, food wastes) into a humus-like material called compost. Composting is essentially the application of controlled conditions (e.g., the optimum recipe of organic materials, aeration, turning and mixing, time) to enhance a natural decomposition process [1]. School and its surrounding cannot be used as a garbage dump because it can cause disease. Sustainable organic waste management becomes an important need to address the negative impact of organic waste and the preservation of the school environment.

Generally, organic waste or organic materials (such as leaves, food scraps, and others) will decompose in nature by microbes and another soil biota. However, the composting process that occurs naturally takes time and slowly. If organic waste is not well managed, it can cause a negative impact on the school environment and also on the quality of health of students in the school. Therefore, a solution is needed to address the use of organic waste in an effort to create a healthy, clean environment and it can provide economic benefits to schools. Organic waste can be easily managed to be composed by utilizing organic waste on composting homes with science-based learning in primary schools.

In this study, students in SDN 1 Biromaru and SD Inpres Kotapulu are a pilot project of 7 learning standards, it calls $7 \mathrm{~K}$ which means students' character building and as ADIWIYATA school in Sigi district. Thus, the environment agency of Sigi regency provides assistance to those elementary schools in the form of compost house and organic waste processing machinery and tools for organic sprouts processing in the environment of both schools.

\section{METHODS}

This research uses descriptive quantitative methods.The data analysis is processed by Milles and Huberman model through data collection phase, data reduction, data display, and conclusion. The data is obtained through document review, interviews, observation and test research (action research). Components of data collected in the form of students knowledge of the benefits of organic waste based on science learning, student character of organic waste processing and the benefits of organic waste processing for the school environment on the compost house.

The steps of organic waste processing, from taking and sorting of organic waste in the school environment up to the organic compost production process is conducted by students student of grade $5^{\text {th }}$ and $6^{\text {th }}$ on a scheduled basis, namely:

1) Garbage collection from classrooms, offices, canteen, school garbage cans, and schoolyard;

2) Waste separation at composting house (students);

3) Garbage Stashing at the compost house (teachers and students);

4) Fermentation in compost house (machine of fermentation);

5) Composting process of garbage (compost house); 
6) Packaging products Organic compost (product marketing by students).

\section{RESULTS AND DISCUSSION}

Organics waste is contained $25-30 \%$ of daily waste. This waste includes items such as grass clippings, yard trimmings, leaves, food scraps, etc. Actually, most of these materials need not be considered as waste. Because they can easily be transformed into a useful soil amendment through a process, it's called composting. Schools are encouraged to reduce their food waste by separating excess food for donations and composting the remainder. Reducing, donating and composting excess food can have a major impact on "greening" and it can minimize spending our money [2]. Concerns about the state of the environment in elementary schools have not been included as specific subjects in the curriculum, but environmental awareness studies are implicitly included in science subjects. In order to cultivate awareness about cleanliness in schools, students are involved in picketing activities of cleanliness groups in each class. Garbage from the classroom and in the schoolyard is collected around the school and then burned.

As mention before, the composting process that occurs slowly. Therefore, to accelerate the composting process, it has been developed by many technologies. Good composting starting uses a simple technology, medium, and high technology.However, it needs to be taught to students based on the level of understanding. So, they can be able to develop knowledge.

The development of composting technology is based on the process of decomposition of organic matter that occurs naturally. The decomposition process is optimized in such a way that composting can run more quickly and efficiently. Composting technology is now very important, especially to overcome the problems of organic waste, such as to solve the waste problem in school and its surrounding. A student who is walking through gardens on the way to and from school encourages their sense of environmentally. Students are also to develop and to connect with the natural world [3].

Nowadays, natural resources are limited, financial resources are often insufficient, and securing land for final disposal is getting more difficult. Therefore, city authorities should set policy directions aiming for managing resource efficient and recycle-based society So, they can provide a clean, healthy and pleasant living environment to their citizens for current and future generations [3]. Collaborative efforts between schools and related institutions have already been conducted, such as collection, transportation and handling garbage in schools only by burning garbage or disposing it outside the school. These efforts are of no use to science learning in elementary school. To overcome the accumulation of waste, then Regional Environmental Agency (Badan Lingkungan Hidup Daerah) on Sigi district allocate aid budget to build a place of organic waste processing known as the compost house with size 6 × 5 meters.

The existing and mature composting technology already offers economically and environmentally interesting solutions that could substantially improve the hitherto used system of waste management. The core of the waste management system is the technology which is applied to the waste from its generation to disposal as happen in Mesir and a number developed countries [4].

Organic waste processing in composting house is based on science learning in. elementary school, It is done by students and teachers through several stages. The important thing in this process is analyzing needs factor. Preparation of land for garbage processing into organic compost into one thing to be carefully calculated. Organic waste mainly consists of food, vegetable, fruit, paper and agricultural waste etc. These types of Organic wastes are biodegradable in nature and vermicomposting is the best option which helps in degradation of solid wastes. Incorporation of vermicomposting to soil improved soil physical and biological Properties [5].

In summary, there are six main steps in the process of composting the waste house, which is: (1). The waste was taken from class trash cans, offices, canteen, and schoolyard. Then the waste is brought to the compost house; (2). Waste is sorted according to its type, organic waste is processed in garbage house; (3). Organic waste is chopped or cut by garbage cutting machine to produce waste material of the size of $1-1.5 \mathrm{~cm}$. This is done to facilitate the process of composting; (4). Preparing organic waste compost material and some EM4 and sugar materials. All ingredients are fed into the composter and ready for processing, (5). The composting process begins. In the process, the composter is set for 15 minutes 4 times a day. This is done to maintain the temperature of the composter so as not to happen the temperature is too high.

All organic waste processing activities in the house of garbage are involving a male and female student of grade 5th and 6th of SDN 1 Biromaru and SD Inpres Kotapulu Sigi district. Processing of organic waste is directly supervised by teachers who have followed the training about waste processing assisted at Regional Environmental Agency (BLHD) in Sigi district. It appears that some students are enthusiastic about this program. This indicates that if organic waste processing is linked with science learning and environmental preservation will be a fun learning. Utilization of organic waste can also generate school income and the product can be marketed to the community.

Before the program, there was a compost house in both schools. However, students are understanding of waste processing was still very low. The landfill at the last disposal was burned. But for the organic waste is not directly burned. Organic garbage takes a long time to dry. Usually, the teachers and students just dump the organic waste on holes in the ground and pile it up. It can also make the ground of the school fertile, but it takes a long time to produce compost.

Based on the result of this program, some students have known the benefits of waste both organic and non-organic waste. The data obtained is $53.06 \%$ the benefits of organic waste in science learning, $76.55 \%$ benefits for the character of students, and $79.25 \%$ benefits for the school environment. This can be seen in Figure 1 as follows: 


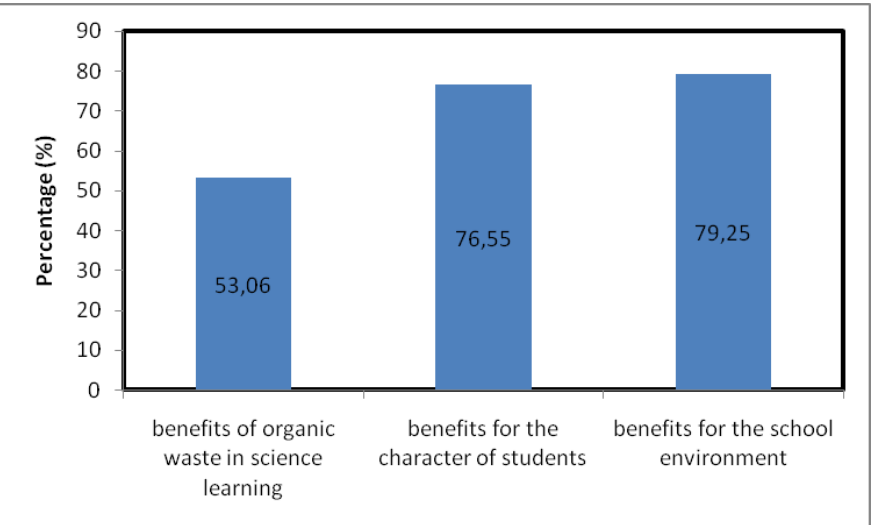

Figure 1. The obtained data in program

Apperception and enthusiasm of the students SDN 1 Biromaru and SD Inpres Kotapulu when handling organic waste into compost is very good and received positive responses from the teachers and the school community. Some teachers thoughts this activity can change attitude and habits of waste management starting from little things, such as starting to dump dry and wet garbage, food scraps from the school cafeteria and leaves in place. Teachers also enthusiastic in this organic waste management activities to be beneficial to the school environment. Some teachers also support how to use organic waste against compost-based home science learning.

Knowledge of sustainable waste management relates and positively contributes to sustainable waste management intentions. Knowledge of cognitive is a very important domain for the formation of one's actions because from experience and research results can be the behavior based on knowledge will be better than not based on knowledge.

The internalization of ecological value has been done through the deepening of awareness of knowledge about organic waste. This activity is done in order to foster the character of students to care about the school environment. Composting is an excellent way to teach students about the life cycle: life, death, decay, and re-birth. When we teach composting, we are teaching how nature recycles. Students learn that by composting, they care for their communities and the natural environment. By adding compost to plants, students learn that healthy soil makes healthy plants and that all humans and animals depend on healthy plants to live. Student will find instructions here on how to build an active compost pile, how to learn about compost critters, and many other fun activities [6].

Students learn to make waste into objects that have aesthetic value and higher economic value by making compost from organic waste and directly processed by the students themselves at the compost house. The result of the students' perception after the internalization of waste utilization to the compost house shows a change in understanding, thinking and attitude toward waste management. Organic samples are no longer considered worthless. It becomes a big advantage for the school.
Efforts made by schools in order to foster student character values is to give the task of collecting garbage, sorting organic waste, making the composting and composting on the house composting. Internalization effort of ecological value is done by planting science knowledge, student character attitude toward organic waste processing and organic waste as a compost to the school environment. Students' understanding of internalization efforts has improved, supporting the establishment of ecological attitudes and behavior through science subjects in elementary schools.

Through the composting of organic trashes to the compost house, the burden of school fees for the purchase of crop fertilizers both in front of the school garden and even on the students' learning gardens can be reduced and soil fertility can be maintained, so schools are more interested in producing their own compost. Both schools are continuously doing organic waste processing to the house to make their own compost and the compost house can be maintained continuously.

\section{CONCLUSION}

The composting process by the student grade $5^{\text {th }}$ and $6^{\text {th }}$ can be used for coaching the character of students, and the benefits for the environment.

\section{ACKNOWLEDGMENT}

The authors acknowledge Regina student of grade 5th and 6th of SDN 1 Biromaru and SD Inpres Kotapulu Sigi district. The authors also thank Department of Education and Culture of Sigi Regency, Central Sulawesi.Regional Environment Agency of Sigi Regency, Central Sulawesi.

\section{REFERENCES}

[1] G. Eason, B. NobleDaftar Pustaka

[2] F. J. Larney, D. M. Sullivan, K. E. Buckley, and B. Eghball, "The Role of Composting in Recycling Manure Nutrients," vol. 1, 2006.

[3] Chittenden Solid Waste District and Intervale Compost Products, "Composting at School," no. 802, 2007.

[4] United Nations, "Municipal Solid Waste Management. Turning Waste into Resources," Shanghai Man. - A Guide. Sustain. Urban Dev. 21st Century, no. 2010, pp. 1-36, 2011.

[5] M. Elfeki and E. Tkadlec, "Treatment of Municipal Organic Solid Waste in Egypt," Environ. Sci, vol. 6, no. 3, pp. 756-764, 2015.

[6] P.B.Londhe, "Recycling of Solid Waste into Organic Fertilizers Using low-Cost Treatment: Vermicomposting," vol. 2, no. 6, pp. 1-11, 2015.

[7] CVSWMD, Do the rot thing: a teacher's guide to compost activities. 2007. 